\title{
Postoperative atrial fibrillation: The truth is stranger than fiction
}

\author{
Paul Kurlansky, MD
}

\footnotetext{
From the Department of Surgery, and the Center for Innovation and Outcomes Research, Columbia University College of Physicians and Surgeons, New York, NY

Disclosures: Author has nothing to disclose with regard to commercial support.

Received for publication March 7, 2017; accepted for publication March 17, 2017.

Address for reprints: Paul Kurlansky, MD, Associate Professor of Surgery, Columbia University College of Physicians and Surgeons, Director of Research, Recruitment and CQI Associate Director, Center for Innovation and Outcomes Research, Black Building 210, CUMC, 650 W 168th St, New York, NY 10032 (E-mail: pk2245@cumc.columbia.edu)

J Thorac Cardiovasc Surg 2017; 154:499-500

$0022-5223 / \$ 36.00$

Copyright (C 2017 by The American Association for Thoracic Surgery

http://dx.doi.org/10.1016/j.jtcvs.2017.03.057
}

Given its prevalence and the bulk of literature it has inspired, it is quite remarkable how little we know about new postoperative atrial fibrillation (POAF). Theories of pathogenesis are certainly plausible-dispersion of atrial refractoriness, increase in phase 3 depolarization, enhanced automaticity, increased interatrial conduction time, decreased conduction velocity, atrial transmembrane potentials, and fluid and electrolyte shifts ${ }^{1}$ —although the variety of theories suggests either a complex mechanism, a lack of clear understanding on our part, or both. Although the list of reported risk factors is extensive, some appear more frequently than others-but none is pathognomonic. ${ }^{2}$ The mere fact that some patients have POAF develop despite evidence-based prophylaxis, while a larger portion do not, even without prophylaxis, suggests that it is neither the substrate nor the surgery alone but rather a combination of the two that can best explain the occurrence. ${ }^{3}$ Even the highly plausible data regarding atrial ischemia and inflammation after surgical insult do not explain a definitive (albeit lower) incidence of POAF after off-pump coronary artery bypass grafting $(\mathrm{CABG})$ or transfemoral transcatheter aortic valve replacement. ${ }^{4}$

How important is it to prevent what ostensibly is a selflimited phenomenon? Here again, data are not clear. Although association with perioperative mortality is commonly reported, POAF's role as an independent predictor is controversial. ${ }^{5-7}$ Association with morbidity appears clearer; however, current data do not permit determination of causality.

It seems reasonable that if a certain substrate predisposes toward POAF, then that substrate might have long-term prognostic implications. Most but not all studies suggest an increased incidence of late atrial fibrillation, while impact on late mortality remains controversial. Interestingly, long-term follow-up of patients undergoing $\mathrm{CABG}$ and aortic valve replacement from the same database during the same period demonstrated that POAF was an independent predictor of late mortality

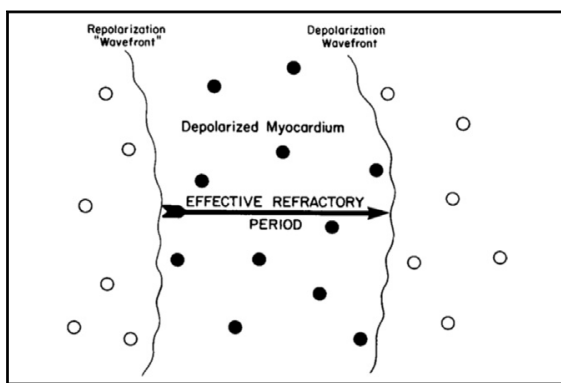

Origin of dispersion of atrial refractoriness. Reprinted with permission.

\section{Central Message}

Despite conflicting reports, there appears to be a time-related impact of postoperative atrial fibrillation on long-term survival.

See Article page 492

in patients undergoing $\mathrm{CABG}$ alone but not those undergoing CABG with valve procedures., ${ }^{8,9}$ The higher overall mortality of the patients undergoing valve procedures may suggest higher competing risks or a difference in how the POAF "substrate" interacts with ischemic versus structural challenges. It is here that the study of Swinkels and colleagues ${ }^{10}$ in this issue of the Journal is welcome and unique. The 18-year follow-up is the longest to date in the literature. The finding that POAF was not an independent risk factor for late mortality is less secure than it might seem. The $P$ value of .052 for the hazard ratio suggests that if the null hypothesis were true, we would expect to find the survival distribution observed only $5.2 \%$ of the time-hardly a resounding endorsement. Examination of the KaplanMeier plots suggests a clear survival benefit for the population without POAF during the first 10 years, with virtual overlapping curves thereafter. Unfortunately, rather than a more robust landmark analysis, Swinkels and colleagues ${ }^{10}$ elected to evaluate the interaction with time in 1-year slices, with a predictable lack of power in any given year to drive significance for the interaction. Nonetheless, the information remains valuable. Whatever the substrate for POAF, it seems that its impact on prognosis may diminish with time. In this confusing arena, any small piece that can contribute to assembling the puzzle is more than welcome. 


\section{References}

1. Maisel WH, Rawn JD, Stevenson WG. Atrial fibrillation after cardiac surgery. Ann Intern Med. 2001;135:1061-73.

2. Mathew JP, Fontes ML, Tudor IC, Ramsay J, Duke P, Mazer CD, et al; Multicenter Study of Perioperative Ischemia Research Group. A multicenter risk index for atrial fibrillation after cardiac surgery. JAMA. 2004;291:1720-9.

3. Cox JL. A perspective of postoperative atrial fibrillation in cardiac operations. Ann Thorac Surg. 1993;56:405-9.

4. Tanawuttiwat T, O'Neill BP, Cohen MG, Chinthakanan O, Heldman AW, Martinez CA, et al. New-onset atrial fibrillation after aortic valve replacement: comparison of transfemoral, transapical, transaortic, and surgical approaches. J Am Coll Cardiol. 2014;63:1510-9.

5. Bramer S, van Straten AH, Soliman Hamad MA, Berreklouw E, Marrtens EJ, Maessen JG. The impact of new-onset postoperative atrial fibrillation on mortality after coronary artery bypass grafting. Ann Thorac Surg. 2010;90:443-9.

6. Villareal RP, Hariharan R, Liu BC, Kar B, Lee VV, Elayda M, et al. Postoperative atrial fibrillation and mortality after coronary artery bypass surgery. J Am Coll Cardiol. 2004;43:742-8.
7. LaPar DJ, Speir AM, Crosby IK, Fonner E, Brown M, Rich JB, et al; Investigators for the Virginia Cardiac Surgery Quality Initiative. Postoperative atrial fibrillation significantly increases mortality, hospital readmission, and hospital costs. Ann Thorac Surg. 2014;98:527-33; discussion 533.

8. Saxena A, Dinh DT, Smith JA, Shardey GC, Reid CM, Newcomb AE. Usefulness of postoperative atrial fibrillation as an independent predictor of worse early and late outcomes after isolated coronary artery bypass grafting (multicenter Australian study of 19,497 patients). Am J Cardiol. 2012;109: 219-25.

9. Saxena A, Shi WY, Paramanathan A, Herle P, Dinh D, Smith JA, et al. A propensity-score matched analysis on the impact of postoperative atrial fibrillation on the early and late outcomes after concomitant aortic valve replacement and coronary artery bypass graft surgery. J Cardiovasc Med (Hagerstown). 2014;15:199-206.

10. Swinkels BM, de Mol BA, Kelder JC, Vermeulen FE, ten Berg JM. New-onset postoperative atrial fibrillation after aortic valve replacement: effect on longterm survival. J Thorac Cardiovasc Surg. 2017;154:492-8. 